\title{
Treating Essence with Essence: Re-inventing bcud len as Vitalising Dietary Supplements in Contemporary Tibetan Medicine
}

\author{
Barbara Gerke
}

\begin{abstract}
Bcud len (pronounced chulen) or 'essence extraction' practices have been described in classical Tibetan medical and religious texts as an element of rejuvenation therapies and preventive antiageing methods. These practices include the ingestion of bcud len pills taken as a dietary supplement or as a substitute for food during meditation and fasting retreats. This paper ${ }^{1}$ discusses how ideas of bcud len are interpreted by Men-Tsee-Khang-trained Tibetan doctors in India as 'health tonics' and 'dietary supplements.' What underlies contemporary Tibetan medical ideas of an 'essence extraction' in relation to Tibetan rejuvenation therapies and pharmacological manufacturing practices of such 'tonics'? I argue that not all bcud len are 'essence extractions' and that what constitutes an 'essence' receives various interpretations by contemporary Tibetan doctors. Ethnographic examples presented are based on postdoctoral fieldwork in Dharamsala, Himachal Pradesh, India (2009-2010).
\end{abstract}

\section{Keywords}

Dietary supplements, essence extraction, bcud len, Tibetan medicine, Tibetan pharmacology, Sorig products

\section{Introduction}

The prolongation of life has occupied people's thoughts in a multitude of different cultural contexts. From myths and folk tales on the 'fountain of youth' to physiological-medical, alchemical, ritual and meditative long-life practices, longevity has been of vital concern in many societies. It has also been an important aspect of Asian medical systems, recently especially in the context of the pharmaceutical manufacturing of rejuvenating and aphrodisiac products, largely marketed as dietary supplements. While a substantial amount of research has been conducted on concepts of immortality and practices of

${ }^{1}$ I am grateful to Stephan Kloos, Jamyang Oliphant, Florian Ploberger, Dr Namgyal Qusar, Dr Lobsang Choejor and two anonymous reviewers for commenting on this paper at various stages. 
rejuvenation and alchemy in the Indian and Chinese contexts, longevity practices in Tibetan societies have only recently begun to be explored. ${ }^{2}$

Among the large variety of Tibetan longevity practices, we also find the socalled 'essence extraction' or bcud len practices. There is, however, no single definition of bcud len as one distinct set of practices. The term bcud len is polysemous, having a variety of meanings in different contexts as the examples from the literature below will show. The Tibetan term bcud can be translated as taste, essence, elixir, sap, moisture, potency, nutrition, extraction, good substance, essential aspects, nutriment, nutritious, vital essence, quintessence, distillation, distilled essence, or a drink. ${ }^{3}$ The verb bcud len $p a$, the Tibetan equivalent of the Sanskrit term rasayyana, means 'extracting the essence' of substances and subsisting on them, but is also used to indicate the preparation of elixirs for the aged, and also the extraction of nutrients from food.

Bcud len involves the extraction of essences from substances, such as stones/ minerals (rdo’i bcud len), soil (sa'i bcud len), roots (rtsa ba’i bcud len), flower petals (me tog gi bcud len), but also from breath (rlung gi bcud len) and awareness (rig pa'i bcud len), which require contemplative meditation skills. Since bcud also means 'to nourish,' the term is used colloquially and as a technical term in the context of tonics, aphrodisiacs and supplements in contemporary Tibetan medical practice; for instance, as part of a product name (for example, the tonic named rgas pa gso ba bcud len chen mo, lit. 'The great essence extraction for the aged', discussed later in this paper). Nourishing substances, such as medicinal butters (sman mar), may also be considered a bcud len.

The main objective of this research project ${ }^{4}$ was to find out how bcud len is interpreted by contemporary Tibetan medical practitioners in India and how ideas of 'essence extraction' are employed in the manufacturing process of Tibetan medical tonics and supplements. Asking Tibetans physicians on how they (re)interpret the bcud len of their classical medical texts in today's clinical contexts involved two key questions: how do such (re)interpretations inform pharmacological production, product design, and marketing? How do Tibetan doctors explain the physiology of how a bcud len product works? This paper presents ethnographic and some textual material on the development and production of institutionalised medical bcud len products from fieldwork with Tibetan medical practitioners at the Men-Tsee-Khang in Dharamsala,

${ }^{2}$ For ethnographies of Tibetan longevity practices, see Gerke 2010, 2012. Examples for textual and anthropological studies of longevity rituals are Cantwell and Mayer, 2008, 2010; Samuel 2010a-c, 2012; Samuel and Cantwell, forthcoming.

3 THL 2010.

${ }^{4}$ This project was kindly funded by a research grant from the Frederick Williamson Memorial Trust, Cambridge, UK. 
Himachal Pradesh, India, in 2009 and 2010. A textual analysis of bcud len ingredients in seminal Tibetan medical texts is presented in another paper. ${ }^{5}$

The term 'supplement,' is defined in the Oxford English Dictionary as 'a substance added to the diet to remedy a deficiency or to enhance (actually or supposedly) growth, health, or well-being'. It has been used in a Western dietary context only since the late nineteenth century. ${ }^{6}$ Contemporary ethnographic research on supplement use in the US has revealed 'a significant disconnect between the "official" discourse surrounding dietary supplements and supplement users' actual practices'. ${ }^{7}$ In the Tibetan context, none of these discourses has been studied as yet. Even though there is no technical Tibetan medical term for a 'supplement' as such, ${ }^{8}$ the idea of a supplement is not unknown in classical Tibetan medical texts. The seminal Tibetan medical text Gyushi (Rgyud bzhi) and its main seventeenth-century commentary Blue Beryl (Bai dìr sngon po) both make a clear distinction between individuals taking bcud len (1) 'on a regular basis' (gtso bor blangs) which 'will obtain benefits in three, six, or twelve months', or (2) 'in addition, if one does not have the time to practise this [long version]'. 'Taking bcud len 'in addition' (zhar la spyad) was explained to me by the senior Tibetan physician Dr Pema Dorje-who is of course familiar with contemporary ideas of supplements—as taking bcud len in addition to a normal diet. He argued that taking bcud len as a supplement is nowadays more popular since only very few people have the time, money and motivation to undergo the months-long bcud len fasting practices. ${ }^{10}$

To understand Tibetan versions of bcud len supplements, we also need to look at the larger context in which strategies of manufacturing and marketing Asian medicines in the form of supplements develop. This process is increasingly influenced by the legal constraints in marketing these products as

5 Gerke, forthcoming.

6 OED 2012.

7 Nichter and Thompson 2006, p. 175.

8 Tibetan terms of the Tibetan Sorig brochure (Ridak 2009, pp. 57, 59; see note 58) that were paraphrased as 'dietary supplements' in the English version are 'tsho ba zas (lit. 'dietary regimes', which is one of the eleven sections of the Explanatory Tantra of the Gyushi) and lus stobs skyed sman zas (lit. 'medicines and foods increasing physical strength'). Tibetan colloquial verbs for 'supplement' or 'supplementing', such as cha tshang bar byed ba (lit. 'to make complete'), kha gsab byed ba, kha skong, sur rgyen, and zur snon byed ba (Acharya 2000, p. 753; THL 2010) are apparently not used in this medical context.

9 zla ba gsum drug lo gcig 'bras bu 'grub / de ma lcogs na zhar la spyad byas pas (Gonpo 1982, p. 81; Sangye Gyatso 1982, p. 362). This 'additional option' only appears in the chapter on 'Normal Health' in the Gyushi. I analyse the chapters on bcud len in these two texts in another paper (Gerke, forthcoming).

${ }^{10}$ Dr Pema Dorje, personal communication, Dharamsala, 24.8.2009 (see also Gerke, forthcoming). 
'medicines'. ${ }^{11}$ Developing herbal products as food supplements is usually the easiest way to gain access to Western markets, since the legislation surrounding supplements is less restricted. ${ }^{12}$ Since there is no 'global' definition of what constitutes 'traditional herbal medicinal products (THMP)', legislation of supplements differs worldwide; in some countries they are considered 'food supplements,' in others they are seen as 'medicines' ${ }^{13}$ sometimes they are camouflaged as 'cosmetics.' Despite blurred boundaries between such classifications ${ }^{14}$ legal restrictions considerably influence the development of supplements in Tibetan pharmacies in Asia. For example, in India the Sorig products can only be licensed under the Indian Cosmetic Act if they do not contain herbs. If they contain herbs-which most of them do-they cannot be licensed and therefore can only be sold at the Men-Tsee-Khang outlets and not in the open market. ${ }^{15}$

This paper presents one of the first anthropological studies on bcud len supplements. Since the overlapping of medical and religious meanings in rejuvenation practices in Tibetan medicine is common, ${ }^{16}$ studies on bcud len have been carried out in various disciplines (Tibetan Studies, Religious Studies, Buddhist Studies, Anthropology). Ching-Hsuan Mei explains bcud len practices in the Nyingmapa tradition of Tibetan Buddhism, showing that bcud len in these early sources has a variety of meanings beyond pills and decoctions used for meditation retreats. ${ }^{17}$ Frances Garrett links bcud len practices to the wider 'nectar' (bdud rtsi) and 'accomplishing medicine' (sman sgrub) practices, mainly in Tibetan literature of the thirteenth century in the context of gastronomical ideas of food, ${ }^{18}$ but also in the context of the medical oriented Yuthok Nyingthik (g.yu thog snying thig) practices. ${ }^{19}$ David Germano mentions bcud len practices as part of Longchenpa's (klong chen rab 'byams pa; 1308-63)

11 Since the European Directive 2004/24/EC took full effect on 30 April 2011, it is now illegal for companies to sell manufactured unlicensed herbal medicines within Europe without the appropriate license i.e. a Marketing Authorization (MA) or a Traditional Herbal Registration (THR). The UK differs slightly from the rest of Europe in that herbal practitioners are to be regulated as from April 2012 allowing for unlicensed manufactured herbal medicines to be prescribed following a face-to-face consultation' (Fan et al. 2012, p. 569).

12 For example, in the USA, the classification of a product as 'dietary supplement' - a subcategory of food-allows the marketing of such supplements without submitting proof of safety or efficacy to the US Food and Drug Administration (FDA) (Denham 2011).

13 See Fan et al. 2012.

14 See Quintus and Schweim 2012.

15 Personal communication, Dr Dawa Ridak, New York, 11.6.2010.

16 See Garrett 2010.

17 See Mei 2010. E-mail communication, Geoffrey Samuel, 15.6.2011.

18 See Garrett 2010.

19 See Garrett 2009a. 
three principles of the yoga of food. ${ }^{20}$ Jamyang Oliphant is translating selected bcud len texts. ${ }^{21}$ One account by a Western Buddhist boud len practitioner describes personal experiences during a bcud len retreat. ${ }^{22}$ Bcud len practices are also mentioned in many biographies of Tibetan lamas. ${ }^{23}$ The composition of a longevity sädhana or a bcud len text seems to have belonged to the religious obligations that almost every high lama in Tibet had to fulfil in his lifetime, which makes them not easy to locate. Bcud len texts are often grouped along with other longevity practices, pervading Buddhist collections. ${ }^{24}$ English translations of these numerous bcud len texts are almost non-existent. ${ }^{25}$

During this project, I came across a detailed description of a contemporary meditative bcud len practice, including a list of bcud len pill ingredients in English. ${ }^{26}$ These pills were prepared by Lama Thubten Yeshe for a bcud len retreat in Dharamsala in 1982; some of the ingredients were purchased from the Men-Tsee-Khang pharmacy at the time. ${ }^{27}$ This boud len recipe, which makes use of two Tibetan precious pills (rin chen ril bu) as well as numerous blessed substances, exemplifies how bcud len practices are part of the wider body of various 'nectar' (bdud rtsi) and 'accomplishing medicine' (sman sgrub) consecration practices that also include empowered medicines. ${ }^{28}$ Another example to support this point is that a number of bcud len ingredients mentioned in Dudjom Rinpoche's commentary (bsNyen yig, Volume Pha, folio 449) are also used in longevity pills and other blessed 'Dharma nectar

\footnotetext{
20 Germano 1997, p. 296.

21 See Oliphant, forthcoming.

22 See Doelter 1983.

23 See, for example, Kongtrul and Barron 2003.

24 For example, the collected works of Mipham Gyatso (1846-1912), the Mi pham rgya mtsho'i gsung 'bum, comprise 27 volumes, seven of which contain about 25 texts or sections on bcud len, Amitāyus and other long life practices (Karma Phuntsok, personal communication, London, 5.6.2004). The Tibetan Buddhist Resource Centre (www.tbrc.org, last date of access: 14.9.2011) lists 106 works on bcud len. One has to take into account here that bcud len often appears in the ornamental title of Buddhist works; so the search result is not a clear indication of how many texts are actually on bcud len practices.

25 Oliphant, forthcoming, will fill parts of this gap. Mullin 1985 translated a flower bcud len text by the second Dalai Lama (see also Gyatso and Rigzin 1982). Emmerick 1990 translated the geriatric chapter of the Gyushi, which contains bcud len recipes. There is also an unpublished translation of a bcud len text by Shardza Tashi Gyaltsen (1859-1934), who wrote 'The Nutrition of Liberation: The Three Kåya "Quintessence-Extraction" (Chulen) From The Dzogchen Spontaneous Arising of the Three Kåyas', translated by Peter Roberts on behalf of the Kalpa Group (C) (I am grateful to Charles Ramble for sharing this reference).

26 See Yeshe 2010.

27 Personal communication, Dr Tenzin Taye, Dharamsala, 24.9.2009.

28 See Garrett 2009a.
} 
medicines' (bdud rtsi chos sman). ${ }^{29}$ As I show later in this paper, sman sgrub rituals are also used to consecrate contemporary bcud len tonics.

It would require extensive research of hundreds of existing bcud len texts to fully understand Tibetan categorisations of bcud len and their contexts. There seems to be a large variety of categories. Here are three examples. The geriatric chapter of the Gyushi distinguishes two types of bcud len: (1) bcud len as a retreat practice and (2) bcud len taken in addition to a regular diet. ${ }^{30}$ Germano distinguishes three types of food yoga, which embrace alchemical bcud len practices, in a text by Longchenpa: ${ }^{31}(1)$ ingesting the extraction of substances, such as meat, stones, herbs etc., (2) 'eating' one's own energised breath, and (3) eating one's excrements. ${ }^{32}$ Kongtrul Rinpoche lists his boud len teachings along with sman sgrub under 'Amrita' (Principle of enlightened qualities) practices. ${ }^{33}$ These comprise almost 300 pages, which again exemplifies the strong link between $b c u d$ len and meditative 'nectar' practices. ${ }^{34}$ These examples show that there are probably as many classifications as there are bcud len practices, although one could identify recurring themes and characteristics in these classifications, such as the following three types.

During my ethnographic and textual research on bcud len in contemporary medical and pharmaceutical practices at the Men-Tsee-Khang in Dharamsala, I identified three types of bcud len practices: (1) bcud len products that are taken as supplements in addition to a normal diet; (2) rejuvenating bcud len, i.e. pills and substances used as a substitute for food during ascetic fasting practices and rejuvenation retreats; (3) meditative bcud len, where essences are extracted from the five elements, sexual fluids, breath, awareness, or the surrounding Buddha fields through visualisation. All these types of bcud len can overlap and intersect with each other in various practices, since 'medicine' in its widest sense 'involves not only the healing of illness but also the enhancing of health, vitality, and power', ${ }^{35}$ for example, by extracting essences (bcud) and lustre (mdangs) from surrounding elements through spiritual practices. The entire process is alchemical in nature since it transforms not only the substances, but also the person who is preparing, consecrating and consuming the boud len.

\footnotetext{
29 See Samuel and Cantwell, forthcoming.

30 Personal communication, Dr Pema Dorje, Dharamsala, 24.8.2009. See also Emmerick 1990.

31 Germano 1997, p. 296.

32 See Garrett 2009b and 2010 for details on such tantric 'nectar' practices.

33 Kongtrul and Barron 2003, p. 522.

34 Garrett 2009a, p. 219.

35 Garrett 2010, pp. 300-1.
} 
As a case in point, bcud len practices might include deity visualisation or sexual union practices to consecrate the bcud len pills used as elixirs for patients or for subsistence during a retreat. ${ }^{36}$ During such retreats, the practitioner undergoes a period of fasting and purification while living exclusively on bcud len pills and performing meditative practices of absorbing energy from 'prāna' (rlung), thereby rejuvenating the body physically and spiritually. ${ }^{37}$ Considering the remoteness of Tibetan mountainous areas where food was difficult to procure but which meditators preferred for such retreats, living on bcud len also had a strong practical relevance.

\section{'Essence extractions' as part of Tibetan 'nectar' practices}

The recent research by Garrett has highlighted Tibetan forms of taking all kinds of substances in the form of transformed and consecrated 'nectar' (bdud rtsi). ${ }^{38}$ Garrett views these practices within the discourse of gastronomy and consumption as an aspect of Tibetan culture and food and shows that these practices are largely linked to the tantras of the Nyingmapa school of Tibetan Buddhism. As those they influenced and cannot be clearly demarcated from medical practices of 'accomplishing medicines' and 'extracting essences'. Medicines that involve the purification of mercury and metals (btso thal) also include some of these 'nectar' substances. ${ }^{39}$ All these preparations are part and parcel of a varied set of practices linking medicine to religion and vice versa. A vast amount of literature on these preparations gives testimony of the popularity they held in Tibet.

With detailed studies (such as Garrett's) emerging, we can slowly understand the range of ideas surrounding the consumption of numerous 'essences' or 'nectars', may it be in the form of medicines, blessing pills, elixirs, or visualised consecrated 'nectars', During the thirteenth century in Tibet, tantric 'nectar' practices occurred parallel in both medical and religious writings, and were often written by the same authors. ${ }^{40}$ Also, the Gyushi, which became the prominent medical text in Central Tibet from the thirteenth century onwards, ${ }^{41}$

\footnotetext{
36 Parfionovitch, Dorje and Meyer (eds) 1992, pp. 119-22.

37 See, for example, Gyatso and Rigzin 1982, and Yeshe 2010. Some of these bcud len practices also involve taking other medicines. Namkhai Norbu Rinpoche mentions a mercury pill as 'medicine' to be used for overcoming hunger in the 'Dharmakāya-style' bcud len of Dzogchen practice (White 1996, p. 385, note 127).

38 Garrett 2010.

39 Gyatso 1991.

${ }^{40}$ Garrett 2010, p. 307.

${ }^{41}$ Garrett 2010, p. 302.
} 
includes the use of elixir recipes for treating the aged as well as mercury recipes for a variety of diseases. The geriatric chapter in the Gyushi (chapter 90, 'Oral Instruction Treatise') offers a range of longevity elixir recipes. ${ }^{42}$ They involve similar kinds of ideas and use a similar rhetoric of consecration as described by Garrett for 'accomplishing medicines' and other 'nectar' practices. The 'nectars' and 'essences' of the bcud len recipes mentioned in the Gyushi, for example, are all based on the idea that certain substances contain bcud, which can be extracted, concentrated into an elixir, and consumed in a consecrated form to enhance vitality and prolong life. The geriatric chapter in the Gyushi mentions - among many other ingredients, which cannot be discussed herea list of 'four nectars' (rtsi bzhi) ${ }^{43}$ and 'five essences' (dwangs ma lnga). ${ }^{44}$ The 'four nectars' and 'five essences' also appear in Vajrayāna longevity practices, such as the 'Chi med srog thig of the Dudjom tradition. ${ }^{45}$ The 'four nectars' are used in bcud len recipes because of their vital, partly evergreen nature. As the Men-Tsee-Khang pharmacist Dr Tenzin Taye explained, 'they are very strong and their leaves feel sticky and juicy. Two of them (shug 'bru and ba lu) remain green throughout the winter. They have potency (nus pa). ${ }^{46} \mathrm{He}$ then referred to a Tibetan medical dictionary, which states that the '['four nectars'] do not dry in winter and therefore become the nourishment of the life-force'. ${ }^{47}$ Their appearance in both medical and ritual contexts supports the wide-spread belief in Tibetan societies that vital essences can be extracted from the outer elements and made available for humans to support health and physical vitality. In the following, I introduce some contemporary tonics, manufactured at the Herbal Product Research Department at the Men-Tsee-Khang in Dharamsala and sold under the trade name of Sorig, ${ }^{48}$ and analyse their related ideas to bcud len.

42 See Gerke, forthcoming.

43 According to Parfionovitch, Dorje and Meyer (eds) 1992, p. 275, the 'four nectars' are juniper seeds (shug 'bru, Juniperus indica), rhododendron flower (bal u me tog bcas pa, Rhododendron Capitalum Maxim), ephedra (mtshe, Ephedra sp.), and tansy (mkhan pa, Artemisia sp./ Tanacetum sp.).

44 The 'five essences' are: (1) mineral exudates/bitumen (brag zhun), (2) calcite (cong zhi), (3) raw sugar (bu ram), (4) honey (sbrang rtsi) and (5) milk and butter (mar dkar). They are said to carry the essential vitality of earth $(s a)$, stones $(r d o)$, wood/trees (shing), flowers (me tog), and roots/grass $(r t s a)$ respectively and in turn restore the flesh $(s h a)$, bones (rus), physical strength (stobs), radiance/lustre (mdangs), and nutrition (bcud) (Gonpo 1982, p. 549).

45 See Samuel and Cantwell, forthcoming.

46 Personal communication, Dharamsala, 24.9.2009.

${ }^{47}$ dgun mi skams pa tshe yi gsos su' 'gyur (Wangdu 1982, p. 479).

48 Sorig is the abbreviation of gso ba rig pa, which means 'science of healing' and is the common Tibetan term for 'Tibetan medicine'. 


\section{The field site and the Herbal Product Research Department}

The fieldwork took place in the north-western Indian state of Himachal Pradesh, which has large Tibetan communities, with 18,150 Tibetans living in and around Dharamsala. ${ }^{49}$ Dharamsala, and especially the Tibetan enclave of McLeod Ganj in upper Dharamsala, with about 9,500 Tibetans, ${ }^{50}$ is one of the main centres of the Tibetan exile community in India and the home of the Fourteenth Dalai Lama.

The Men-Tsee-Khang, with its famous Tibetan medical college, large pharmacy and clinics, is located on the hillside between McLeod Ganj and Dharamsala. It is not only the largest medical institution in Tibetan exile, ${ }^{51}$ it is increasingly catering to foreign and Indian patients ${ }^{52}$ not only through its clinics, but also through their Sorig rejuvenating tonics, aphrodisiacs and wellness products.

The majority of Tibetan medical practitioners in India are trained at the Men-Tsee-Khang. Today, Tibetan medical students are also taught Western anatomy, chemistry and biology, and many of them have science backgrounds from their higher secondary degrees. These Tibetan doctors speak English, Tibetan and Hindi and are largely able to communicate with Tibetan, foreign and Indian patients in all of these three languages and thus translate their medical ideas not only between three languages but also within various cultural and medical belief systems..$^{53}$ Many of them are sent abroad for short periods of time on certain Men-Tsee-Khang projects to teach and see patients and are thus familiar with Western culture to varying degrees. Tibetan medicine in Indian exile is 'remarkably homogenous... with the vast majority of its practitioners, whether practicing privately or in an institution, having been trained under the Men-Tsee-Khang's syllabus'.$^{54}$ During fieldwork, this general homogeneity of institutionalised education often led to Tibetan physicians referring to the same corpus of medical texts in response to my textual questions. Nevertheless, in the context of medical practice, I found that MenTsee-Khang doctors themselves had their own personal views on the Sorig bcud len products. While some prescribed them as supplements, others did not. Some even disregarded them as 'commercial bcud len', arguing that 'real

\footnotetext{
49 See CTA, Planning Council 2000.

50 See Prost 2008.

${ }^{51}$ For a history of the Men-Tsee-Khang, see Kloos 2008, 2010.

52 Kloos quotes from the Men-Tsee-Khang annual report that between 2007 and 2008, 92 per cent of all Men-Tsee-Khang patients were Indian (Kloos 2010, p. 82).

${ }^{53}$ For an example of such cultural translations of medical terms, see Gerke 2011.

${ }_{54}$ Kloos 2010, p. 16.
} 
essence extractions' are too difficult to manufacture on such a large scale of production.

In 1994, the Herbal Product Research Department was established by Tsering Tashi, the Men-Tsee-Khang director at the time, as a subsection of the Clinical Research Department. Under the guidance of the senior Dr Tenzin Choedrak and the two physicians, Dr Namgyal Qusar ${ }^{55}$ and Dr Lhawang, ${ }^{56}$ both of the Research and Development (R\&D) Department, it began producing the first Tibetan Herbal Tea and beauty products (e.g. 'White Lotus' beauty cream). In 1995, Dr Namgyal Qusar was instrumental in developing the first tonic called gso rig stobs sman (today sold under the name stobs sman bcud 'dus rgya mtsho). Sorig Products were produced by the R\&D Department from 1994 to 1999 under the supervision of Dr Namgyal Qusar with the aim to finance Men-Tsee-Khang's research projects. ${ }^{57} \mathrm{With}$ the growing success of these products, a separate unit under the name Herbal Product Research Department was opened in 1999, and Dr Lhawang was appointed head of this department. It is located on the hillside below the pharmacy, consisting of a four-storied building with several work units. The department has a few machines to fill the Sorig tea bags and make sachet packets for the tonics, which are sold in the form of granules.

By the end of 2009 (Dr Dawa Ridak had been head of the department from 2003 to 2009), altogether 45 products had been developed and a detailed 90-page brochure, which Dr Ridak had designed, was published in Tibetan and English. ${ }^{58}$ The products are sold at the over 50 Men-Tsee-Khang branch clinics around India and Nepal, online via the official Men-Tsee-Khang website, through an Export Department in Delhi, ${ }^{59}$ and various foreign distributors. ${ }^{60}$ The distributor for Europe, 'Tibetan Therapeutics', based in London, sells only eight of the supplements, among them all four products introduced in this paper, which shows that these are popular products in the

55 Dr Namgyal Qusar was deputy director of the R\&D department from 1994 to 1999.

56 Dr Lhawang was deputy director of the R\&D department from 1998 to 2003.

57 Personal communication, Dr Namgyal Qusar, Dharamsala, 15.5.2012.

58 See Ridak 2009. The brochure can be accessed online in English and Tibetan at http:// www.men-tsee-khang.org/hprd/hprd-history.htm (last date of access: 22.2.2012). The Herbal Product Research Department also distributes smaller information leaflets on the products in English and Tibetan for distributors.

59 Their webpage http://www.tibetan-medicine.org is linked to the official Men-Tsee-Khang website http://www.men-tsee-khang.org/index.htm. Last date of access: 1.3.2012.

${ }^{60}$ As of 1.3.2012, the Sorig products had three official distributors in the West, for Europe www.tibetan-therapeutics.com, for Estonia www.sorig.ee, and for Canada www.tibet-treasure.com. Since April 2012, the Shang Shung Institute has also made Men-Tsee-Khang Sorig products available in the United States via their online store. See: http://shangshung.org/store/index. php? main_page=indexercPath=138 (last date of access: 31.8.2012). 
West. The income generation for the Men-Tsee-Khang through the sale of Sorig products is substantial. In 2008, the Herbal Product Research Department generated approx. 1 crore $(10,000,000)$ Indian Rupees (approx. 154,000 Euro) turnover and 50 lakh $(5,000,000)$ Indian rupees profit (approx. 78,000 Euro), which was about a fourth of the Men-Tsee-Khang's annual turnover that year. ${ }^{61}$ In India, the products are sold for an affordable price, following Men-Tsee-Khang's policy to serve the underprivileged sections of society.

At the beginning of this project (August 2009), Dr Dawa Ridak had just left the Herbal Product Research Department for the USA and Dr Lobsang Choejor, who had previously worked as a medical practitioner at a Men-TseeKhang branch clinic near Kathmandu, had taken over as the new head of department. Fortunately, I was able to interview Dr Dawa Ridak later in New York. In Dharamsala, I also spoke with the senior physicians Dr Pema Dorje, Dr Namgyal Qusar (who established his independent clinic close to Dharamsala), the pharmacists Dr Tenzin Taye and Dr Ngawang Soepa, and informally with several other Men-Tsee-Khang-trained doctors.

I was not allowed to see the manufacturing process or take any photographs inside the department and had to rely on the Sorig brochures, the packaging descriptions, and interviews with Tibetan doctors. Unfortunately, I also did not get access to official sales figures that would reveal who were the main customers of particular Sorig bcud len products.

\section{The Sorig products}

In 2010 (and still at the time of the publication of this paper in 2013), four categories of Sorig products were manufactured: (1) 'supplements' (nine products including tonics and spices), (2) 'health drinks' (14 types of herbal teas), (3) 'incense' (two types of incense), and (4) 'skin \& hair care' (20 types, including creams, oils, lotions, balms, talcum powder, medicinal baths, shampoo and an aroma therapy diffuser). ${ }^{62}$ A variety of tonics are manufactured and sold in the first Sorig product series called 'supplements.' They offer examples of contemporary interpretations of medical concepts of bcud len, which will be discussed below. Several of these supplements use the term bcud len, either in their product names or product description in the accompanying leaflets.

To avoid confusion with the terminology used for these products, we need to differentiate between the terms 'medicine' (sman), 'tonic' (stobs sman, lit.

${ }^{61}$ Kloos 2010, pp. 171, 287.

${ }^{62}$ See http://www.men-tsee-khang.org/hprd/product.htm (last date of access: 6.4.2013). 
'strength medicine'), 'vitamin' (stobs sman, bcud sman, zungs, stobs skyed, also sman mar and boud rdzas, lit. 'nourishing substance'), 'aphrodisiac' (ro rtsa sman), and 'essence extraction' (bcud len). Although some of the Sorig herbal tonics are called stob sman, for example, stobs skyes sman ja (lit. 'medicinal tea to increase strength'), ${ }^{63}$ none of these products are considered a sman or medicine as such. Sman are strictly defined as products that have been manufactured at the Men-Tsee-Khang pharmacy. Dr Dawa Ridak explained the difference: 'When you are sick, then you take medicine (sman). The herbal products are supplements for the prevention of illness.' ${ }^{64}$ The pharmacy, however, produces certain aphrodisiacs ( ro rtsa sman), which are also called 'tonics', but as I was told by Dr Tenzin Taye, they are considered sman 'because they also treat other diseases, such as low kidney function or sexual disorders, and are only prescribed after consultation with a Tibetan doctor'. ${ }^{65}$ Thus, even though Tibetan doctors call some of their supplements sman, they have a clear idea that these are not medicines, but supplements. Likewise, there is a distinction between bcud len and ro tsa. Dr Pema Dorje clarified the difference: 'While bcud len can be ro tsa, ro tsa cannot replace bcud len' ${ }^{66}$ In other words, while essence extractions might increase sexual vigour, they are not mere aphrodisiacs.

How do Tibetan physicians differentiate between a 'vitamin' and a bcud len? The English term 'vitamin' is often used to explain in English what boud len means. My question 'what is bcud len?' was several times responded to in English with 'bcud len is like a vitamin'. Contemporary Men-Tsee-Khang doctors conceive of a vitamin as a substance that vitalises. The term apparently comes closest to their medical perceptions of a bcud len supplement when explaining this to Westerners. However, when asking further, they distinguish between age target groups; while bcud len are particularly aimed at the age group above 50 or 60 , tonics and vitamins can be taken by all age groups.

\section{Treating essence with essence}

How do Men-Tsee-Khang doctors explain the effects of contemporary bcud len products in terms of the medical physiology described in their main text, the Gyushi?

\footnotetext{
63 Sold under the label 'Tonic Tea', this tea is one of the 14 Sorig tea products made from 11 herbs that are said to prolong the life-span, increase bodily strength, enhance the complexion, and control premature wrinkles and grey hair (Ridak 2009, p. 30).

64 Personal communication, New York, 11.6.2010.

65 Personal communication, Dharamsala, 24.9.2009.

${ }^{66}$ Personal communication, Dharamsala, 24.8.2009.
} 
During a discussion on bcud len in preparation for the 2009 IASTAM conference in Bhutan, where this paper was first presented, Dr Pema Dorje said, 'Because the lus zungs bdun are in themselves essences extractions, they are strengthened through bcud len, which are also essence extractions.' ${ }^{67}$ This comment illustrates the parallels between ideas of vitality-enhancing bcud len substances and the distillation process of food essences in Tibetan physiology. Digestion and distillation have long been linked in Asian medical systems as a way of reaching perfection ${ }^{68}$ and also play out in religious practices. Garrett remarks that the 'understanding of human by-products as purified distillations of religious practice or moral perfection is also supported by South Asian and Tibetan presentations of how food creates the body' ${ }^{69}$ A brief description of the classical Tibetan medical version of the digestive distillation process will help us to understand Dr Pema Dorje's statement.

The Tibetan lus zungs bdun (lit. 'seven body maintainers')—also translated as 'bodily constituents', 'bodily energies', or 'body supporters'-are equivalent to the seven dhätus in Āyurveda. The Gyushi describes the physiology of the digestive process of the lus zungs bdun as a continuous process of refining essences from the five elements (space, water, fire, earth and wind) and the six tastes (sweet, sour, salty, bitter, hot and astringent), ingested in the form of food. ${ }^{70}$

According to the Gyushi, the digestive process takes six days and is as follows: the essence of food is refined through six stages from the organic food sap, or chyle, into blood, flesh, fat, bone and bone marrow, finally becoming the regenerative fluids (semen or blood; $k h u b a$ ). Desi Sangye Gyatso in his seventeenth-century commentary to the Gyushi, the Blue Beryl, points out that it is characteristic of this process that the essence of one stage is transformed entirely into the constituent of the next stage, expelling all impurities (snyigs) that are created during this distilling process in the form of excretions, such as faeces, urine, nails, hair etc., and transforming the essence of each of the lus zungs into the next stage. ${ }^{71}$ The final product of this refining process is a supreme vital essence (Tib. mdangs or mdangs mchog; Skt. ojas). The quality of mdangs mchog shows in the person's radiance and lustre; it is vulnerable to emotional stress and can be lost through anxiety. Consequently, mdangs mchog has to be understood not as an organ-related idea but as an expression of healthy lus zungs.

67 Personal communication, Dharamsala, 24.8.2009.

68 Alter 1999.

69 Garrett 2010, p. 323.

70 Gonpo 1982, pp. 25-9; Men-Tsee-Khang 2008, pp. 68-79.

71 Sangye Gyatso 1982, p. 120. 
I think that Garrett's observations on the parallel transformation processes taking place with human substances in sman sgrub practices as well as in digestive physiology are also applicable to transformative ideas underlying $b c u d$ len products. She suggests that 'we could see in Accomplishing Medicine two parallel transformative processes: the ritual transformation of human byproducts (or whatever substances are consumed under their name) into nectar in the course of a tantric sädhana, on the one hand, and the physiological transformation of foods, such as nectar preparations, into the perfected essence of the body, the reproductive substance, in the course of digestion, on the other. ${ }^{172}$ Similarly, while making and consecrating a bcud len product a certain transformation of bcud into an essence takes place. Distilling this $b c u d$ further through ingesting it transforms and affects the zungs and the final essence, mdangs mchog. Therefore, 'treating the essence with an essence' involves corresponding transformative processes that collectively promote vitality.

The close proximity of 'semen' ( $k h u b a$ ) and its essence, mdangs mchog, in this chain of distilled essences also alludes to the closely-linked concepts of sexual power and radiant vitality, which is also evident from the visualised sexual union practices. These form an essential part of the consecration of bcud len, where divine semen becomes an important substance of vitality that is visualised as a blessing flowing into the elixirs that are being consecrated and enhanced with power and vitality. Despite these connections between meditative sexual union practices and actual vital essences, sexual abstinence (chags spang) is considered essential during bcud len practices, a point made both in the Gyushi $i^{73}$ and by lamas guiding bcud len retreats. Lama Yeshe, for example, warns that 'experiencing strong sexual pleasure during this retreat is extremely dangerous'; instead the revitalised strength from the aphrodisiac component of the bcud len pill should be completely directed to gain 'penetrative concentration' in meditation. ${ }^{74}$

Since Tibetan doctors have the understanding that food can be transformed into essences, and that the entire digestive process is in itself an extraction of essences, it comes as no surprise that they would make use of an external essence to treat the bodily essences and strengthen them with the objective to enhance vitality and long life. They consider 'mdangs mchog as the base on which to promote longevity. ${ }^{35}$ If the lus zungs are well supported with a good diet, mdangs mchog will reap the greatest benefit of the transformation and create the radiant vitality of a person. As the last essence created in the

72 Garrett 2010, p. 324.

73 Gonpo 1982, p. 81.

74 Yeshe 2010.

75 Personal communication, Dr Pema Dorje, Dharamsala, 24.8.2009. 
distillation process, mdangs mchog is on the top of the internal food chain, so to speak. This process is also linked to the basic principles of Tibetan medical physiology, the three nyes pa —rlung, mkhris pa and bad kan — which build the body-mind complex within the five element cosmology. ${ }^{76}$ The three nyes $p a$ influence a person's vitality because 'the balance of rlung, mkhris pa and bad kan support the seven lus zungs and in effect promote mdangs mchog. ${ }^{77}$

How is this essence-distilling process articulated in the context of the Sorig products? What kind of language is used to demonstrate this process in English to a largely Western or modern Indian-educated clientele?

\section{Taking the essence as a supplement}

In the following, I briefly introduce four of the 46 Sorig products that present themselves as rejuvenating tonics, bcud len, or aphrodisiacs in one form or another. Three contain the word $b c u d$ in their names, two are called $b d u d r t s i ;^{78}$ both $b c u d$ and $b d u d$ rtsi are also translated as 'elixir' in the English brochure. ${ }^{79}$ None of these are bcud len products for fasting meditation retreats; they are nourishing supplements to improve health and vitality.

\section{'Health Tonic'}

This tonic was first made in 1996 under the name of gso rig stobs sman. ${ }^{80}$ The literal translation of the name of the current product is 'invigorating medicine, ocean of assembled essences' (stobs sman bcud 'dus rgya mtsho). The English brochure presents this product as a 'boosting tonic' that strengthens the immune system, promotes as sense of well-being, restores energy, clears the senses, helps in dealing with stress, and thus supports a long and healthy life. The effect of the tonic is explained in terms of maintaining the 'kidney heat', which in Tibetan physiology is always linked to sexual stamina (symbolised by the kissing couple on the package; see fig.1). A loss of 'kidney heat'

\footnotetext{
${ }^{76}$ For those unfamiliar with three nyes pa: rlung is governed by the wind element and responsible for all movements in the body; mkhris pa has the nature of fire and rules metabolic processes; and bad kan is governed by water and earth and binds substances in the body together. There is plenty of secondary literature around explaining these nyes pa in great detail.

77 Personal communication, Dr Pema Dorje, Dharamsala, 24.8.2009.

${ }^{78}$ One of these 'nectar' products, which is not introduced here, is called 'wisdom nectar' (blo 'phel bdud rtsi). It is given to strengthen memory in children (Ridak 2009, p. 14).

79 Ridak 2009, pp. 12, 15.

${ }^{80}$ Personal communication, Dr Dawa Ridak, New York, 11.6.2010.
} 


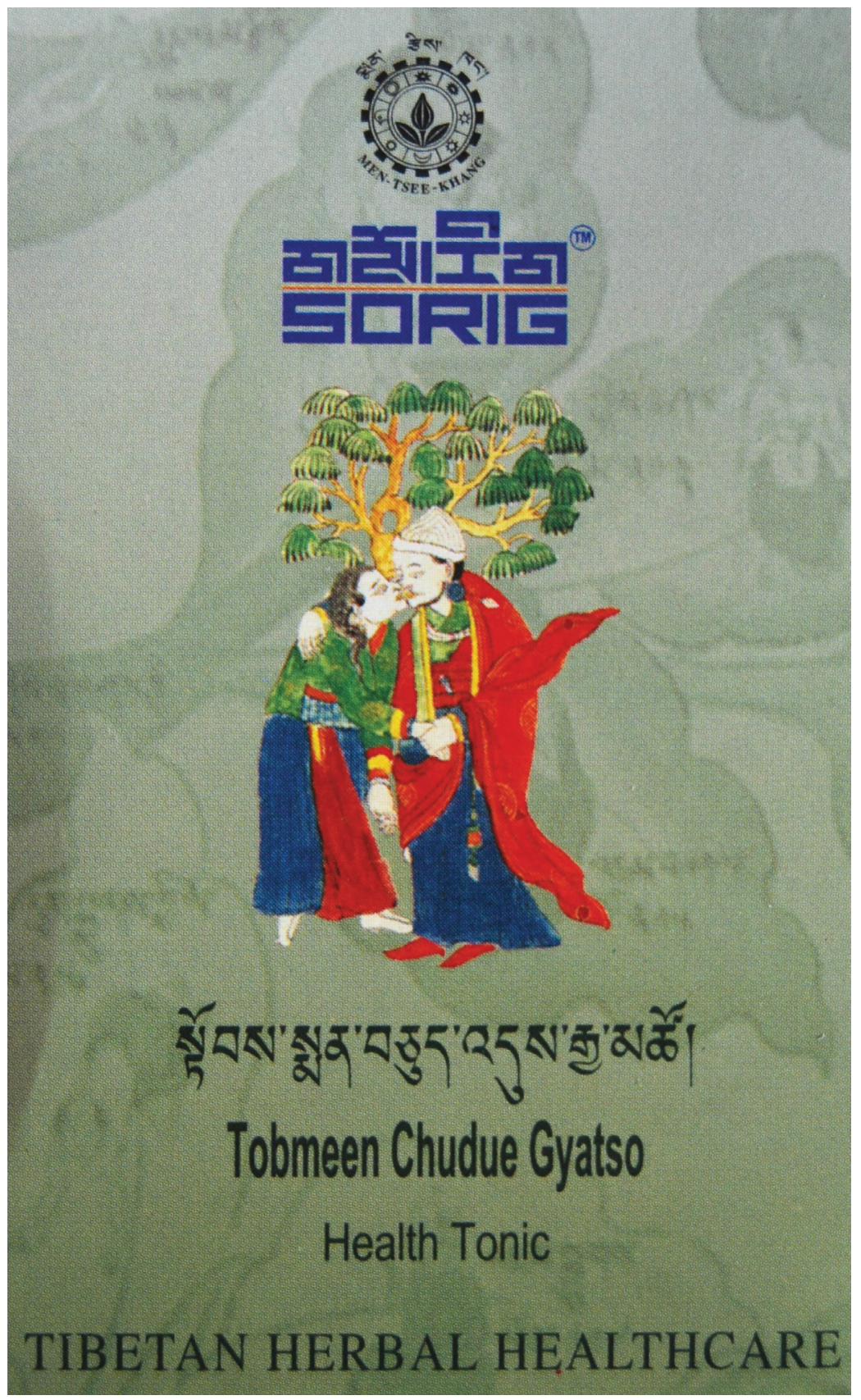

Fig. 1 
can lead to a loss of vitality. ${ }^{81}$ The Tibetan version is shorter and mentions the strengthening of the bodily elements, the increase of mdangs, the improvement of 'kidney heat', and the clearing of the senses. According to Dr Pema Dorje, 'this type of boud len is like a ro tsa sman', ${ }^{82}$ i.e. an aphrodisiac. However, the label sman here does not automatically make the product a 'medicine', as explained earlier.

As for the design of the product packaging, Dr Dawa Ridak was inspired by images from the seventeenth-century medical thankas. He said that some Tibetans took issue with the image of the kissing couple on the package, but he felt it was appropriate since it was taken from the thankas commissioned by Desi Sangye Gyatso himself and thus was part of Tibetan medical tradition. ${ }^{83}$

\section{'Elixir of Rejuvenation'}

This product is said to be particularly beneficial for the elderly. It is called 'Elixir of Rejuvenation' (rgas pa gso ba boud len chen mo; lit. 'the great essence extraction for the aged'; see fig. 2). The English brochure explains the reasons for ageing according to the Gyushi, and presents this product as a 'chulen, or energy booster', which 'slows down the collective signs of ageing'. It also stresses its qualities as an 'aphrodisiac'. Instructions include taking the 'pulverised herbs' from the first day of the waxing moon and exercising until sweating. ${ }^{84}$ Dr Tenzin Taye describes it as 'giving energy to elderly patients. However, it is warming, so not good for liver problems and in cases of fever. ${ }^{95}$

This is the only Sorig product that gives specific meditation instructions on a separate leaflet, describing a longevity practice involving visualisations that facilitate the extraction of $b c u d$ from surrounding elements as well as the recitation of the Amitāyus (Buddha of Long Life) mantra. These instructions are meant for those patients who wish to consecrate the supplement they are taking. This is not unusual, since even Men-Tsee-Khang precious pill prescriptions contain instructions on how to consecrate them with the Medicine Buddha mantra before taking them. What is unusual is the shift away from this practice being conducted by the physician/pharmacist ${ }^{86}$ to the practice being made available to the patient or anybody buying this bcud len product via the internet. This consecration practice is also more complex than the

81 Ridak 2009, p. 11.

82 Personal communication, Dharamsala, 24.8.2009.

83 Personal communication, New York, 11.6.2010.

84 Ridak 2009, p. 12.

85 Personal communication, Dharamsala, 24.9.2009.

86 The Gyushi describes two such consecration practices, which are also depicted on two of the medical thankas (Parfionovitch, Dorje and Meyer (eds) 1992, pp. 119-22, 275-8). 


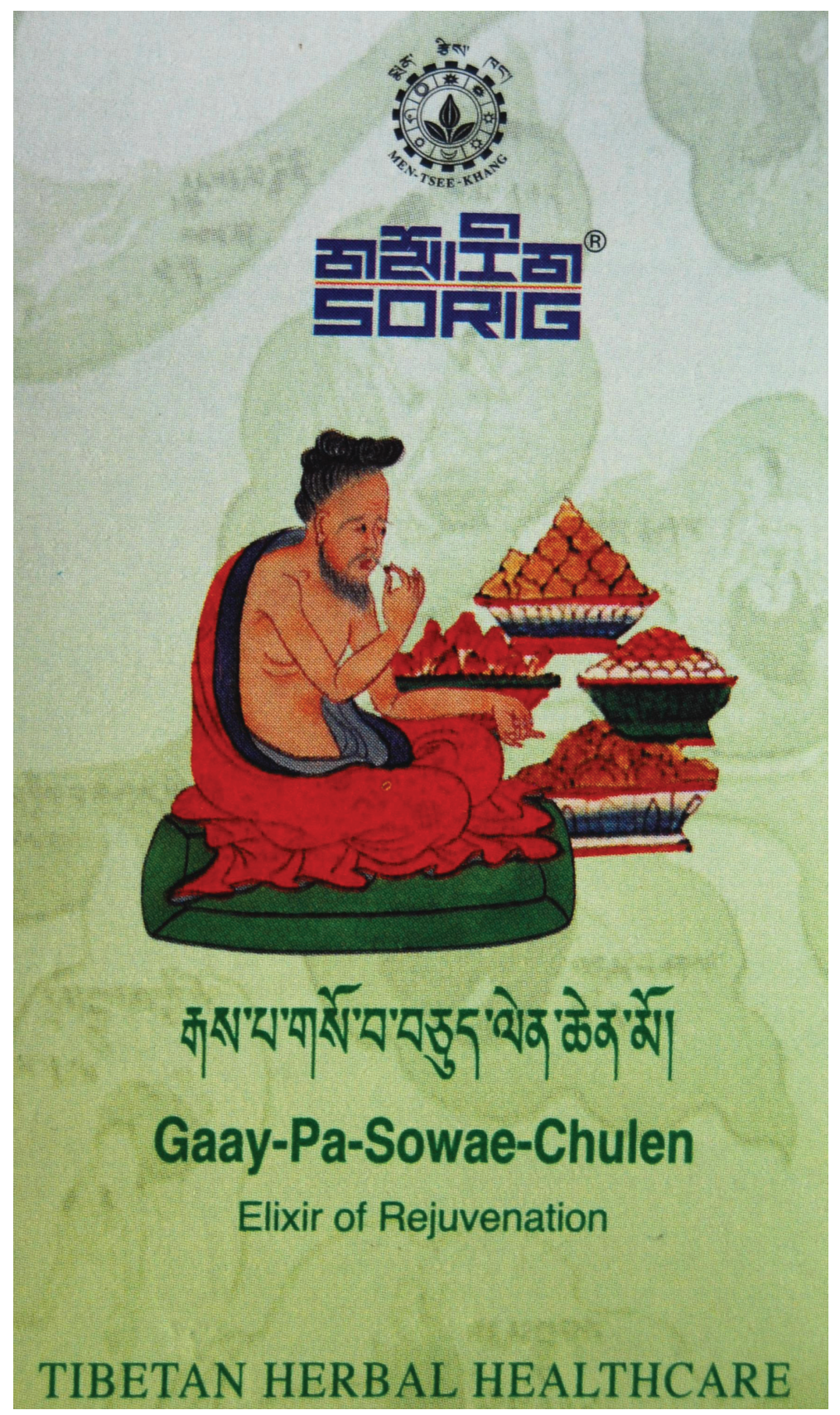

Fig. 2 
popular Medicine Buddha mantra instructions that are distributed along with precious pills. I asked Dr Dawa Ridak how and why this leaflet was created. He explained:

I requested Khen Rinpoche Lobsang Tenzin in Sarnath to compile this short practice for patients. Yuthok Yontan Gonpo himself spoke about it, but the problem is that many cannot practise at length. We made it short and accessible for everyone to do this. Actually, it is important to have the initiation and transmission from an experienced and good lama, but for this short practice, you do not necessarily need this. If you have faith, you will receive some blessings. Also it depends on your motivation. Actually, it was compiled to help those who believe in Buddhist ideas, but there are also suggestions that those who follow other religious traditions can do this. If you are a Christian, you can visualise your Christian deity. ${ }^{87}$

\section{'Energize the Body'}

This 'Chongchen Chulen' (gcong chen ${ }^{88}$ bcud len; lit: 'chronic wasting elixir'; see fig.3) is presented as 'body energizer' said to provide vital nourishment to the body. It is also called a 'chulen, or energy booster', aimed at patients with chronic illnesses, respiratory problems and lack of appetite. It rebuilds the 'body's natural strength and immune system' and strengthens the 'activities of the sexual organs', but is not called an aphrodisiac as such. ${ }^{89}$ Dr Pema Dorje gives this tonic to tuberculosis patients.

\section{'Boost the Life-span'}

This product was first made in $2004 .^{90}$ It is called 'Tsephel Dhutse' (tshe 'phel bdud rtsi, lit. 'life-span increasing nectar'). The English brochure labels it 'elixir of life', and describes it as a 'potent elixir' that helps to rebuild and strengthen a weak body, bones and the immune system. It contains herbs and minerals. Instructions include the Amitāyus mantra, which should be recited while taking the elixir and which 'should evoke a strong sense of prolonged life'. ${ }^{91}$ The image on the package shows a mother giving musk water to her child (see fig.4). ${ }^{92}$

\footnotetext{
${ }^{87}$ Personal communication, New York, 11.6.2010.

${ }^{88}$ Gcong chen refers to a long-lasting chronic illness, such as tuberculosis.

${ }^{89}$ Ridak 2009, p. 13.

${ }^{90}$ Dr Dawa Ridak, personal communication, New York, 11.6.2010.

${ }^{91}$ Ridak 2009, p. 15.

92 The image was modified from thanka 45, figure 48, in Parfionovitch, Dorje and Meyer (eds) 1992, p. 262.
} 


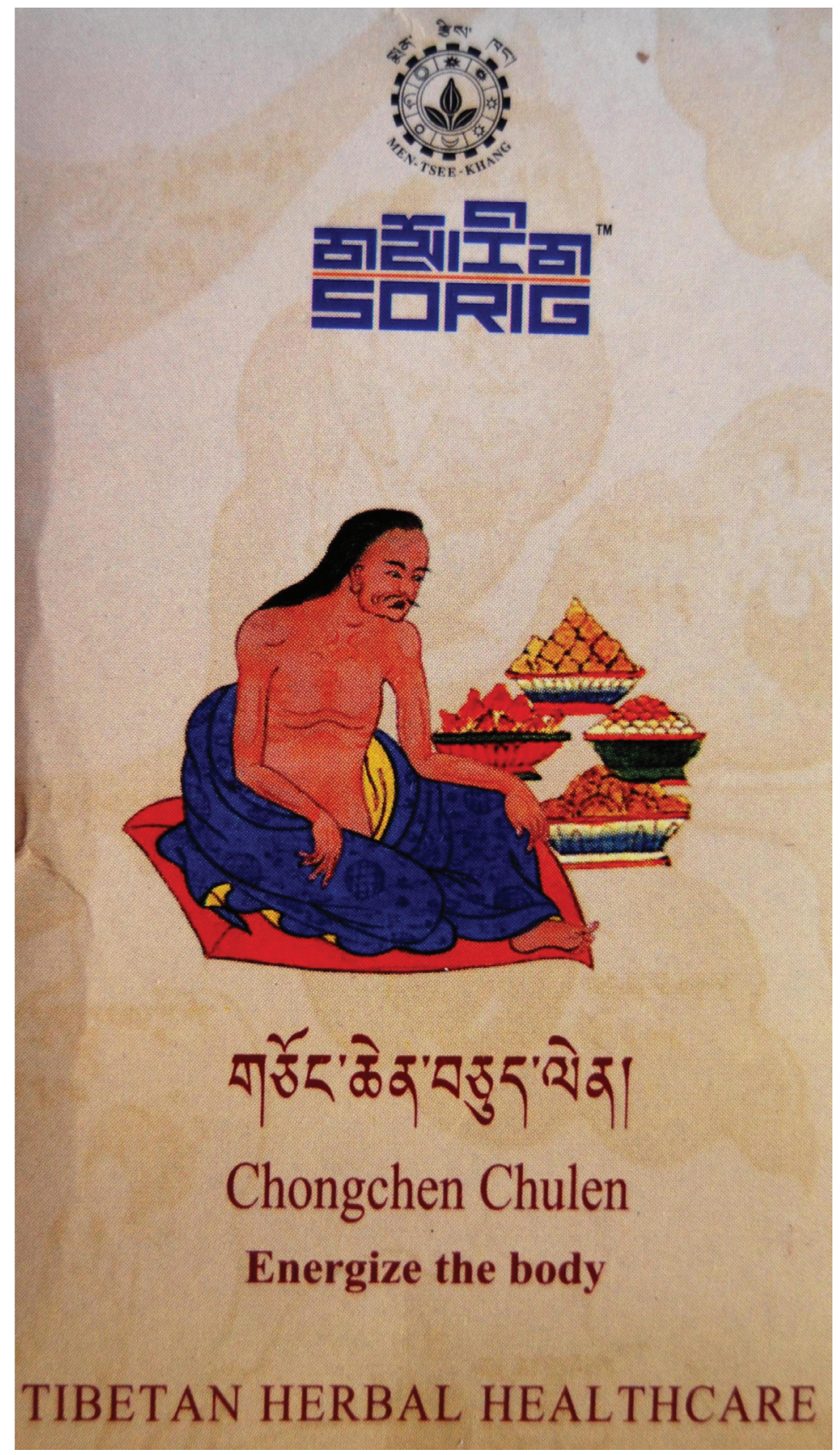

Fig. 3 


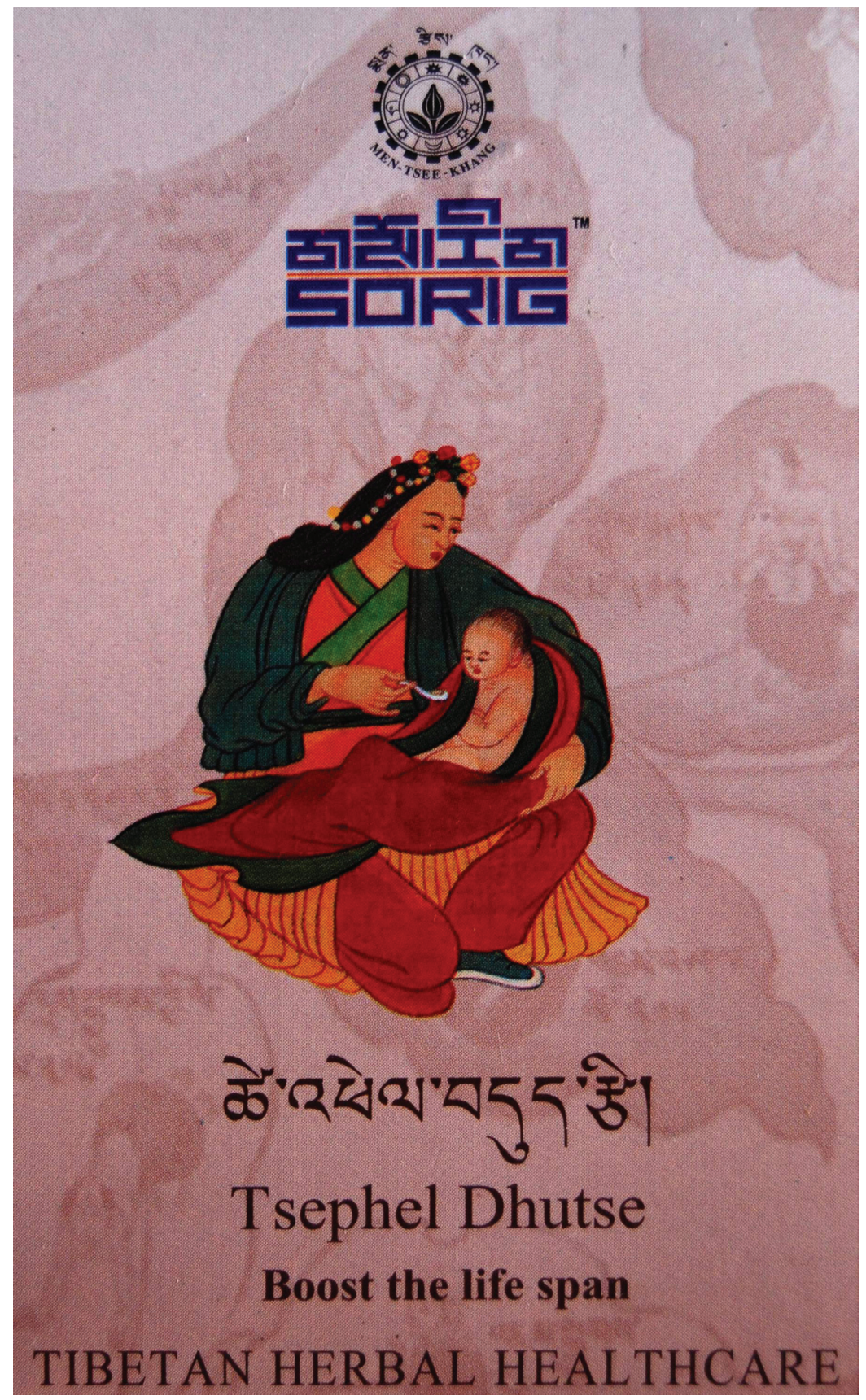

Fig. 4 


\section{The rhetoric of the product descriptions}

In the following, I analyse the language that is used in the English and Tibetan brochures to explain and promote these tonics. Terms such as 'immune system' appear frequently in the English version. Classical Tibetan medicine has no concept of an immune system as such, but the Sorig brochures paraphrase Tibetan ideas of vitality and bcud len in Western terms that are commonly associated with anti-ageing, sexual vigour, well-being and tonics. Dr Dawa Ridak said, 'When the body is strong, life will be long. That is how we understand the immune system.' In the Tibetan version, the benefit of the products is expressed in terms of 'developing radiance and strength of the body' (lus khams kyi mdangs stobs rgyas pa) ${ }^{93}$ or 'increasing the strength of zungs' (zungs stobs skyed). ${ }^{94}$ Dr Lobsang Choejong explained that here zungs refers to the lus zungs bdun in general, but particularly to the second of the seven lus zungs, the 'vitalised blood' (zungs khrag). 'Blood' is considered the most important of the lus zungs and can be strengthened with bcud.

To compare the Tibetan and English product descriptions of Tsephel Dhutse is illuminating. ${ }^{95}$ In the Tibetan brochure, this product is clearly advertised for children, to increase the strength of their zungs and prolong their lives (byis pa'i zungs stobs skye la tshe ring du 'phel); its benefit is to conquer all diseases and evil spirits (nad gdon rnams 'joms pa'i dge phan yod). ${ }^{96}$ Both statements are missing in the English version, which is neither addressing a particular age group, nor diseases, nor evil spirits, but instead emphasises the balancing of 'body energies' and the 'mind-body' health-promoting aspects of this 'potent elixir', including strengthening the 'immune system'. The instructions for the accompanying spiritual practice are more detailed in the Tibetan brochure and refer to Tibetan Buddhist practices of reciting mantras for a certain amount of time. In this case, to prolong the life of the child, the Amitāyus mantra should be recited in the morning after washing, on an empty stomach, as many times as possible. For children above one year, one sachet is given every three days and for highly emaciated children one sachet with milk every day. The English version is brief, just mentioning the mantra and the instruction to recite it as many times as possible while drinking the herbal mixture. This brief comparison shows that the English brochure-while exactly the same in lay-out and design - is not a translation of the Tibetan

\footnotetext{
93 Ridak 2009, p. 11.

94 Ridak 2009, p. 15.

95 Ibid.

96 The Gyushi describes children's diseases frequently being caused by evil spirits ( $g$ don; Jäger 1999).
} 
version but a text on its own, specifically catering to a foreign and/or modern Indian clientele, as much as the Tibetan version is making use of popular Tibetan cultural practices, catering to Tibetan-speaking clients. Moreover, only the Tibetan version uses the term 'disease' ( $\mathrm{nad}$ ), ${ }^{97}$ the English versions of both the glossy brochure and the leaflet for distributers emphasise the 'supplement' nature of the products. Terms, such as 'medicine' and 'disease', that could be legally problematic when selling the products as food supplements in the West, are avoided.

\section{Manufacturing and consecrating $b c u d$ len tonics}

Sorig bcud len and tonic preparations claim to have been 'formulated according to Tibetan Medical Texts'.$^{98}$ Dr Dawa Ridak explains that the bcud len products are all based on recipes mentioned in the Oral Instruction Treatise, which, with 92 chapters, is the largest of the four treatises of the Gyushi. The 'Elixir of Rejuvenation' is based on a recipe from the geriatric chapter (rgas pa gso ba; chapter 90); the 'Health Tonic' is from the chapter on virility (ro tsa ba byar ba; chapter 91); the 'Chongchen Chulen' recipe is based on the chapter on great consumption disease (gcong chen zad byed bcos pa; chapter 11), and the 'Tsephel Dhutse' recipe on one of the chapters of children's diseases (byin nad; chapters 71-3). ${ }^{99}$ These recipes have been modified by Dr Dawa Ridak according to what is available and practical in today's manufacturing process. For various reasons, these details are not mentioned in the brochure, nor are the complete lists of ingredients given on the packages. These recipe sources give insight into the broader application of bcud len supplements beyond geriatrics. The recipes to increase bcud are not limited to the aged but appear also in the context of nourishing children, rebuilding strength after chronic illness and increasing sexual drive. They are meant to nourish and support convalescence after a prolonged illness, strengthen the lus zungs, as well as improve sexual vigour and vitality through increasing the digestive and kidney heat.

The compounding methods of these products also vary. In the geriatric chapter of the Gyushi, we find that soaking, boiling, straining and mixing in more ingredients in the process of 'extracting an essence' are key features of making boud len; albeit these are not the only methods used in bcud len recipes. ${ }^{100}$ Not everything that is being extracted becomes a bcud len and not every

\footnotetext{
97 Ridak 2009, pp. 13, 15.

98 Ibid.

99 Personal communication, New York, 11.6.2010.

100 Gerke, forthcoming.
} 
bcud len is being extracted. The pharmacist Dr Ngawang Soepa explained it this way: 'An extraction of Agar 35 is not a bcud len. Not everything cooked and extracted becomes bcud len. On the other hand, cong zhi (calcite) as such is not a bcud len, but through the process of extraction it gains in bcud and becomes a bcud len. ${ }^{101}$ Dr Tenzin Taye explained that there are also powerful ingredients that contain high levels of bcud that would be destroyed through cooking and extraction processes. In those cases, these ingredients are just cleaned, ground and added to the bcud len mixture without much processing. ${ }^{102}$ Thus, 'extracting the essence' does not always involve complex manufacturing procedures of extraction.

Now follows the description of a contemporary method to make bcud len supplements used at the Herbal Product Research Department in Dharamsala. When I asked Dr Lobsang Choejor how their bcud len is prepared he explained the method as follows:

We first weigh all ingredients and grind them into a fine powder, excluding those which should not be ground, such as honey, molasses and brag zhun (shilajit or bitumen), which are dissolved into a liquid solution. The powder is then mixed with the solution into a dough ( pag). Some ingredients are boiled, others are just ground. The base of the granules is rice dough ('bras rtsam). With the help of a net we make the granules. Through the net we can keep their sizes small. Then we dry the granules for three to four days, either outside when the weather is good or inside the drying room when it's rainy or foggy. Then the granules are sent for quality control to the Men-Tsee-Khang laboratory. Only when we get the confirmation from the laboratory that they are completely dry and the quality has been approved, will we pack them well and store them in large containers. Once we receive a larger order, let's say for 500 packets, we'll pack the granules into the little paper sachets, with the help of a machine. Thirty sachets fit into one package. Then we dispatch them for sale.

What kind of medical ideas inform these manufacturing processes?

Dr Lobsang Choejor linked bcud len to the term nus pa, which means 'power' or 'potency' and is widely used in Tibetan pharmacology. Along with 'strength' (stobs) and 'quality' (yon tan), nus pa is one of the three main parameters of Tibetan pharmacology, explained in chapter 20 of the Explanatory Tantra (bshad rgyud). ${ }^{103}$ Apart from the eight traditional nus pa (heavy, oily, cool, blunt, light, rough, hot and sharp), according to which medicinal ingredients are classified in terms of potency, nus pa also indicates simply the power a substance has. Dr Lobsang Choejor explained this as follows:

101 Personal communication, Dharamsala, 6.8.2009.

102 Personal communication, Dharamsala, 24.9.2009.

103 Men-Tsee-Khang 2008, pp. 199-224. 
Bcud len means that some of the ingredients that are inside the preparation have the power of bcud len. Because they have bcud, they have nus pa. So there is power and energy. If I give this bcud len to a weak person after a chronic illness, his energy will be restored. The body itself will take out the bcud from the preparation.

Dr Choejor's comments show that medical ideas of bcud len do not necessarily refer to pharmaceutical methods of essence extraction. The essence bcud can also be extracted inside the body from the products that contain substances that are high in bcud. The point I want to make here is that in explaining the workings of bcud len, doctors might situate the act of 'extracting the essence' into the body itself, relying on the digestive distillation process to extract the bcud from the product ingredients and create good lus zungs.

Finally, I want to comment on the consecration of contemporary bcud len products. In a bcud len recipe, as in other sman sgrub and bdud rtsi preparations, blessed substances are transmitted through a kind of 'ongoing fermenting substance' ( phab rta rgyun ldan), sometimes called 'mother pill', which is added to future boud len, medicines or longevity pills. The phab rta, literally translating as 'yeast', is a portion from a previous batch of pills, which is added to future batches of pills, similar to the continuation of a bread-starter made from sourdough. The phab rta guarantees a continuity of sacredness in pills across many generations of lamas. ${ }^{104}$ Sometimes, high lamas give their personal phab rta to the pharmacist who makes their bcud len pills. The MenTsee-Khang pharmacy and the Herbal Product Research Department do not use phab rta. However, they do guarantee their continuity of blessings through adding sacred substances from the Dalai Lama's temple in the form of 'mantra pills' ( $m a$ ni ril bu $)^{105}$ and 'Dharma nectar medicine' (bdud rtsi chos sman). ${ }^{106}$ In addition, they conduct their own sman sgrub consecration ritual every two to three years at the Men-Tsee-Khang. Dr Dawa Ridak said that after they completed the first bcud len products in 2004, he organised a seven-day sman sgrub ritual at the Men-Tsee-Khang with monks from the Dalai Lama's Namgyal Monastery conducting the ritual. The ritual text used was from the Yuthok Nyingthik Cycle. ${ }^{107}$ All of these consecrated substances are added to each fresh batch of Sorig products and Men-Tsee-Khang-made medicines, following a similar concept of continuity as in the usage of phab rta.

\footnotetext{
104 See Samuel and Cantwell, forthcoming, for phab rta in longevity pills.

105 These pills are consecrated with the mantra of Avalokiteśvara, om mani padme hung.

106 There exists a large variety of such 'Dharma' pills, prepared by Buddhist lamas from relics and various mineral, plant and other substances, which are consecrated in rituals and shared with disciples to confer blessings and wisdom and protect from diseases and malevolent spirits.

107 See Garrett 2009a.
} 
They accumulate blessings and nus $p a$, thus interlinking 'essence-extractions', 'nectars' and 'accomplishing medicines'.

\section{Concluding remarks}

This paper introduced ideas of bcud len in contemporary Tibetan supplements that are sold as 'tonics', 'essence extractions' and 'elixirs'. I did not analyse the actual ingredients of bcud len supplements, ${ }^{108}$ but tried to understand how contemporary Tibetan medical practitioners in India view and utilise ideas surrounding bcud len in the development and promotion of new Men-TseeKhang supplements. I argued that not all bcud len are 'essence extractions' and that what constitutes an 'essence' receives various interpretations by contemporary Tibetan doctors. Medical ideas of ways in which essences can be extracted include a range of methods which can be pharmacological, meditative or physiological in nature. All of them, however, are aimed at extracting bcud from material or spiritual substances for the revitalisation and strengthening of the body.

The range of interpretation of bcud in the various Sorig products introduced in this paper, as well as the differences in compounding methods, show that there is no single definition of a bcud len in Tibetan medicine. Contemporary medical practitioners have skilfully made use of the polysemous nature of $b c u d$ len to create new, popular, income-generating products and promote them in ways palatable to their Tibetan, Indian, and foreign customers.

The commercial viability of Sorig products cannot be overlooked. It is reflected in the Men-Tsee-Khang sales figures and in the ways in which the products are promoted online and in the English brochure and leaflet. Despite certain legal restrictions, the production of Sorig tonics are a successful incomegeneration project for the Men-Tsee-Khang. It is the tonic and elixir aspect of bcud len practices that sells, not the purification and fasting aspect. While the Gyushi explains that rejuvenating boud len can only have effect when the body is cleansed, ${ }^{109}$ such purification drugs (enemas, purgatives) are not produced at the Men-Tsee-Khang or sold as part of the supplements. ${ }^{110}$ Manufacturing simple tonics that can be taken as supplements open global market opportunities, avoiding legal restrictions attached to the sale of 'medicines'. While some doctors prescribe Sorig products to their patients, others dismiss them as 'commercial bcud len'. Thus, there are a variety of views in the Tibetan medical

108 For bcud len ingredients mentioned in the Gyushi, see Gerke, forthcoming.

109 Emmerick 1990.

110 Dr Ngawang Soepa, personal communication, Dharamsala, 6.8.2009. 
establishment concerning concepts of bcud len and not all agree with the concept of bcud len as portrayed by Sorig products.

Despite commercial dimensions and global regulations, consecration remains an essential 'ingredient' of the products. The fact that sman sgrub rituals are performed regularly at the Men-Tsee-Khang to consecrate the bcud len tonics (and other medicines) reaffirms Garrett's earlier statement that 'although the bud len and sman sgrub traditions do have distinct bodies of literature, the practices are closely intertwined and share many techniques and theories' ${ }^{111}$ The blessed substances from the Dalai Lama's temple make the products also attractive for Tibetans who live far away from Dharamsala but want to remain linked to the blessings of the Dalai Lama. The self-consecration of supplements is also made more accessible to clients through printed leaflets about meditative consecration practices that can be practised without empowerments and teach patients how to extract essences and bless the substances they take through visualisation and across religious beliefs. In sum, Tibetan notions of 'elixirs', 'nectars', 'tonics' and 'essences', which are concerned with vitality and rejuvenation, are both employed and adapted for contemporary use in the production and promotion of Sorig supplements.

\section{References}

Acharya Karma Monlam (ed.) 2000, The New English-Tibetan Dictionary, Dharamsala: Department of Education CTA Dharamsala.

Alter, J. S. 1999, 'Heaps of Health, Metaphysical Fitness: Ayurveda and the Ontology of Good Health in Medical Anthropology', Current Anthropology 40, supplement: 43-66.

Cantwell, C. and R. Mayer 2008 (unpublished paper), 'Imagery for Creating Longevity: Artwork used for the 'Chi med srog thig', Paper presented at the panel 'Theory and Practice of Healing, Medicine and Longevity in Buddhism', XVth Conference of the International Association of Buddhist Studies (IABS), Atlanta, Georgia, 23-28 June 2008.

- 2010, 'The Creation and Transmission of a Textual Corpus in the Twentieth Century: The 'Chi med srog thig', in A. Chayet, C. Scherrer-Schaub, F. Robin and J.-L. Achard (eds), Edition, Éditions: L'écrit au Tibet, Évolution et Devenir, Munich: Indus Verlag, 65-83.

CTA (Central Tibetan Administration-in-exile, India), Planning Council 2000, Tibetan Demographic Survey 1998, Dharamsala: Planning Council, Central Tibetan Administration, Gangchen Kyishong.

Denham, B. E. 2011, 'Dietary Supplements-Regulatory Issues and Implications for Public Health', JAMA 306: 428-9.

Doelter, J. 1983, 'Experiences on the Pill', Magazine of the Foundation for the Preservation of the Mahayana Tradition (London/Ulverston): 28-9. See also: <http://www.lamayeshe.com/ index.php?sect=article\&id=489> Last date of access: 29.2.2012.

${ }^{111}$ Garrett 2009a, p. 212. 
Emmerick, R. E. 1990, 'rGas-pa gso-ba', Buddhica Britannica Series Continua II-Indo-Tibetan Studies: 89-99.

Fan, T. P. et al. 2012, 'Future Development of Global Regulations of Chinese Herbal Products', Journal of Ethnopharmacology 140: 568-86.

Garrett, F. 2009a, 'The Alchemy of Accomplishing Medicine (sman sgrub): Situating the Yuthok Heart Essence in Tibetan Literature and History', Journal of Indian Philosophy 37: 207-30.

_. 2009b, 'Eating Letters in the Tibetan Treasure Tradition', Journal of the International Association of Buddhist Studies 32: 85-114.

_ 2010, 'Tapping the Body's Nectar: Gastronomy and Incorporation in Tibetan Literature', History of Religions 49: 300-26.

Gerke, B. 2010, 'The Multivocality of Ritual Experiences: Long-Life Empowerments among Tibetan Communities in the Darjeeling Hills, India', in J. Weinhold and G. Samuel (eds), 'The Varieties of Ritual Experience', section IV of 'Ritual Dynamics and the Science of Ritual. Volume II-Body, Performance, Agency, and Experience' (eds Axel Michaels et al.), Wiesbaden: Harrassowitz, 423-41.

- 2011, 'Correlating Biomedical and Tibetan Medical Terms in Amchi Medical Practice', in V. Adams, M. Schrempf and S. Craig (eds), Medicine Between Science and Religion: Explorations on Tibetan Grounds, Oxford, New York: Berghahn Books, 127-52.

- 2012, Long Lives and Untimely Deaths: Life-span Concepts and Longevity Practices among Tibetans in the Darjeeling Hills, India, Leiden, Boston: Brill.

_. Forthcoming, "Treating the Aged" and "Maintaining Health": Locating bcud len Practices in the rGyud bzhi'.

Germano, D. 1997, 'Food, Clothes, Dreams, and Karmic Propensities', in D. S. Lopez, Jr. (ed.), Religions of Tibet in Practice, Princeton, NJ: Princeton University Press, 293-312.

Gonpo, Yuthok Yontan 1982, Bdud rtsi snying po yan lag brgyad pa gsang ba man ngag gi rgyud, Lhasa: Bod ljongs mi dmangs dpe skrun khang.

Gyatso, Gyalwa Gedun and Tsepak Rigzin (transl.) 1982, 'Extracting the Essence (bcud len) by Gyal-wa Gen-dun Gya-tso, The Second Dalai Lama (1475-1542)', Tibetan Medicine 5: $87-104$.

Gyatso, Yontan 1991, 'The Secrets of the Black Pill Formulations', Tibetan Medicine 13: $38-55$.

Jäger, K. 1999, "Nektar der Unsterblichkeit" Zwei Kapitel aus der Tibetischen Kinderheilkunde: Übersetzung aus dem tibetischen Originalwerk und Kommentar, Engelsbach/Frankfurt a.M.I München/New York: Hänsel-Hohenhausen.

Kloos, S. 2008, 'The History and Development of Tibetan Medicine in Exile', Tibet Journal 33: $15-49$.

- 2010, Tibetan Medicine in Exile: The Ethics, Politics, and Science of Cultural Survival, $\mathrm{PhD}$ thesis, University of California San Francisco and Berkeley.

Kongtrul, J. L. T. and R. Barron 2003, The Autobiography of Jamgön Kongtrul: A Gem of Many Colors, Ithaca, NY: Snow Lion Publications.

Mei, C.-H. 2010, 'bCud len Practices in the rNying ma Tradition', unpublished paper presented to the IATS conference in Vancouver, 15-21 August 2010.

Men-Tsee-Khang 2008, The Basic Tantra and the Explanatory Tantra from the Secret Quintessential Instructions on the Eight Branches of the Ambrosia Essence Tantra, Dharamsala: MenTsee-Khang.

Mullin, G. H., Dalai Lama II Dge-Dun-Rgya-Mtsho and Z. Rinpoche 1985, Selected Works of the Dalai Lama II: The Tantric Yogas of Sister Niguma (Teachings of the Dalai Lamas), Ithaca NY: Snow Lion.

Nichter, M. and J. J. Thompson 2006, 'For my wellness, not just my illness: North Americans' Use of Dietary Supplements', Culture, Medicine and Psychiatry 30: 175-222. 
OED (Oxford English Dictionary) 2012, http:/lezproxy.ouls.ox.ac.uk:2277. Last date of access: 1.8.2012.

Oliphant, J. forthcoming, "Extracting the Essence": Ideas and Methods Concerning bcud len in the Tibetan Tradition', DPhil thesis, Oxford University, Oxford.

Parfionovitch, Y., G. Dorje and F. Meyer (eds) 1992, Tibetan Medical Paintings. Illustrations to the Blue Beryl Treatise of Sangye Gyamtso (1653-1705), London: Serindia Publications.

Prost, A. G. 2008, Precious Pills: Medicine and Social Change among Tibetan Refugees in India, Oxford, New York: Berghahn Books.

Quintus, C. and H. G. Schweim 2012, 'European Regulation of Herbal Medicinal Products on the Border Area to the Food Sector', Phytomedicine 19: 378-81.

Ridak, D. 2009, Information of Sorig Herbal Products (bod kyi gso rig gi thon dngos mdzes mdangs), Dharamsala: Herbal Product Research Dept., Men-Tsee-Khang.

Samuel, G. 2010a, 'Inner Work and the Connection between Anthropological and Psychological Analysis', in. J. Weinhold and G. Samuel (eds), The Varieties of Ritual Experience. Section of Ritual Dynamics and the Science of Ritual. Volume II-Body, Performance, Agency and Experience, eds A. Michaels et al., Wiesbaden: Harrassowitz, 299-314.

- 2010b, 'Healing, Efficacy and the Spirits', The Efficacy of Rituals Part II. Journal of Ritual Studies Special Issue, W. S. Sax and J. Quack (eds), 24: 7-20.

—. 2010c, 'A Short History of Indo-Tibetan Alchemy', in M. Schrempf, S. Craig, F. Garrett and M. Cuomo (eds), Health, Illness, and Modernity: Social and Historical Studies of Medicine in Tibetan Contexts (Proceedings of the 11th Seminar of the International Association for Tibetan Studies (PIATS), Königswinter, 27 August-2 September, 2006), Andiast, Switzerland: International Institute for Tibetan and Buddhist Studies GmbH, 221-33.

2012, 'Amitayus and the Development of Tantric Practices for Longevity and Health in Tibet', in I. Keul (ed.), Transformations and Transfer of Tantra in Asia and Beyond, Berlin, Boston: Walter de Gruyter GmbH \& Co. KG, 263-86.

Samuel, G. and C. Cantwell (with contributions from R. Mayer and P. Ogyan Tanzin) forthcoming, The Seed of Immortal Life: Contexts and Meanings of a Tibetan Longevity Practice. Kathmandu: Vajra Books.

Sangye Gyatso, Desi 1982 [completed in 1688], Gso ba rig pa’i bstan bcos sman bla’i dgongs rgyan rgyud bzhi'i gsal byed bai dūr sngon po'i ma lli ka, 2 vols, Lhasa: Bod ljongs mi dmangs dpe skrun khang.

Shardza Tashi Gyaltsen (1859-1934), 'The Nutrition of Liberation: The Three Kåya "Quintessence-Extraction" (Chulen) From the Dzogchen Spontaneous Arising of the Three kåyas', Translation by Peter Roberts on behalf of the Kalpa Group (C).

THL (Tibetan and Himalayan Library) 2010, 'The THL Tibetan Dictionaries. Tibetan to English Translation Tool', URL: <http://www.thlib.org/reference/dictionaries/tibetan-dictionary/ translate.php $>$. Last date of access: 22.02.2012.

Wangdu 1982, G.yu thog gso ba rig pa'i tshig mdzod g.yu thog dgongs rgyan, Lhasa: Mi rigs dpe skrun khang.

White, D. G. 1996, The Alchemical Body: Siddha Traditions in Medieval India, Chicago and London: The University of Chicago Press.

Yeshe, Lama Thubten 2010, 'Taking the Essence', URL: <http://www.lamayeshe.com/index .php?sect=article\&id=47I $>$. Last date of access: 29.2.2012. 